\title{
Tracing in Vivo the Dorsal Loop of the Optic Radiation: Convergent Perspectives From Tractography and Electrophysiology Compared to a Neuroanatomical Ground Truth.
}

\section{Michele Rizzi ( $\nabla$ michele.rizzi@ospedaleniguarda.it )}

ASST Grande Ospedale Metropolitano Niguarda Centro Munari Chirurgia dell'Epilessia e del Parkinson https://orcid.org/0000-0002-7936-6536

\section{Ivana Sartori}

ASST Grande Ospedale Metropolitano Niguarda Centro Munari Chirurgia dell'Epilessia e del Parkinson

\section{Maria Del Vecchio}

National Research Council: Consiglio Nazionale delle Ricerche

\section{Flavia Maria Zauli}

University of Milan Department of Biomedical and Clinical Sciences Luigi Sacco: Universita degli Studi di Milano Dipartimento di Scienze Biomediche e Cliniche Luigi Sacco

\section{Luca Berta}

ASST Grande Ospedale Metropolitano Niguarda: Azienda Socio Sanitaria Territoriale Grande Ospedale Metropolitano Niguarda

\section{Domenico Lizio}

Niguarda Ca Granda Hospital: Azienda Socio Sanitaria Territoriale Grande Ospedale Metropolitano Niguarda

\section{Alessandro De Benedictis}

Ospedale Pediatrico Bambino Gesù: Ospedale Pediatrico Bambino Gesu

\section{Silvio Sarubbo}

Presidio Ospedaliero Santa Chiara: Ospedale di Trento

\section{Valeria Mariani}

ASST dei Sette Laghi: Aziende Socio Sanitarie Territoriale dei Sette Laghi

\section{Khalid Al-Orabi}

ASST Grande Ospedale Metropolitano Niguarda Centro Munari Chirurgia dell'Epilessia e del Parkinson

\section{Pietro Avanzini}

National Research Council: Consiglio Nazionale delle Ricerche

\section{Research Article}

Keywords: white matter, Klinger dissection, visual evoked potential, inter-trial coherence, SEEG, visual system 
Posted Date: June 10th, 2021

DOI: https://doi.org/10.21203/rs.3.rs-589114/v1

License: (c) (1) This work is licensed under a Creative Commons Attribution 4.0 International License. Read Full License 


\section{Abstract}

The temporo-parietal junction (TPJ) is a cortical area contributing to a multiplicity of visual, languagerelated and cognitive functions. In line with this functional richness, also the organization of the underlying white matter is highly complex and includes several bundles. The few studies tackling to date the outcome and neurological burdens of surgical operations addressing TPJ document the presence of language disturbances and visual field damages, with the latter hardly recovered in time. This observation advocates for procedures identifying the optic radiation (OR) bundles crossing the white matter (WM) below TPJ.

In the present study we adopted a multimodal approach to address the anatomo-functional correlates of the dorsal loop (DL) of the OR. In particular, we combined cadavers' dissection with tractographic and electrophysiological data collected in drug-resistant epileptic patients explored by stereoelectroencephalography (SEEG). Cadaver dissection allowed us to appreciate the position and geometrical properties of the DL. More surprisingly, both tractographic and electrophysiological observations converged on a unitary picture highly coherent with the data obtained by neuroanatomical observation.

The combination of diverse and multimodal observations allows to overcome the limitations intrinsic to single methodologies, and to define a unitary picture which makes it possible to investigate DL presurgically and at the individual patient level, aiming at limiting the postsurgical damages. Notwithstanding, such a combined approach could serve as a model of investigation for future neuroanatomical inquiries tackling WM fibers anatomy and function through SEEG-derived neurophysiological data.

\section{Introduction}

The temporo-parietal junction (TPJ) is a complex cortical region involved in many essential functions, including language (within the dominant hemisphere), visual processing and other cognitive abilities (such as arithmetic, writing, symbol processing, working and musical memory) (Martino 2013). In parallel with this functional complexity, TPJ is subserved by an intricate network of several white matter (WM) bundles, including, from the surface to the depth, the superior longitudinal fasciculus, the arcuate fasciculus, the middle longitudinal fasciculus, the inferior longitudinal fasciculus, the inferior fronto-occipital fasciculus (IFOF), the optic radiation (OR), and the tapetum (Martino 2013, De Benedictis 2014).

Over the last decade, studies on the anatomo-functional organization of the TPJ emerged, also thanks to application of traditional methods, such as cadaver dissection (Parraga 2012), ore more innovative techniques, such as diffusion tensor imaging (DTI)-based tractography (Catani 2017), or both (Wu 2018). Growing data coming from direct cerebral electro-stimulation have been also provided (Maldonado 2011; Mandonnet 2017; Rolland 2018), also with the aim of comparing intraoperative results with the anatomical counterparts, according to multimodal frameworks (Sarubbo 2015).

However, to date only few studies tackled the postoperative outcome and potential neurological burden associated with surgeries involving the TPJ and the underlying connectivity (Maldonado 2011; Sanai 2012; Rolland 2018). In fact, language disturbances and visual field damages are reported in the early 
postsurgical period, with possibility of long-term persistence, especially for vision (Sanai 2012; Rolland 2018). In this case, such a visual field deficit depends on the disruption of the OR fibers running within the deep TPJ-WM over the tapetum.

The optic radiation conveys visual information from the lateral geniculate body to the ipsilateral calcarine cortex (Meyer 1907), and to other extra-striatal occipital structures (Yu 2018). Two major components are generally described: a) the inferior bundle (forming the Meyer's loop), and b) the superior bundle, which forms the dorsal loop (DL), forming the WM adjacent to the parietal cortex (Ebeling 1999; Kamali 2014). The inferior bundle has been extensively studied for both research (Lija 2014; Mandelstam 2012; Nowell 2014) and clinical purposes, given the high rate of damage - and consequent visual deficits - encountered during temporal lobectomy (Taoka 2008; Piper 2014). On the contrary, the superior bundle has been more sparsely investigated, despite the fact that its damage results in a contralateral inferior homonymous quadrantanopia with consequent impairment of more vision-related activities than damages of the inferior bundle (Cheng 2015).

Within OR ramifications, the superior bundle is the one candidate to cross the WM underlying TPJ. In a previous study, Burgel and coworkers (Burgel 1999) digitalized myelin-stained histological series relative to 10 patients and co-registered them to corresponding structural magnetic resonance (MR), warping the final results to a reference brain. Following the methods, the authors inferred that the DL course in the deep TPJWM is characterized by a highly variable course among subjects, in some cases skimming the parietal cortex (Burgel 1999). However, no functional evidence is available to date to associate the DL position under the TPJ with the visual deficits experienced upon resective surgery within this region.

To overcome this gap, in the present study we adopted a multimodal approach to address the anatomofunctional correlates of DL. First, we report the structural information on DL's geometrical properties using standard post-mortem dissection approach. Subsequently, anatomical and functional correlates were investigated by means of stereoelectroencefalography (SEEG) performed as preoperative monitoring in patients suffering for drug-resistant epilepsy. Tractography was used to estimate the anatomical arrangement of $\mathrm{DL}$, while intracerebral visual evoked potentials (VEPs) recorded from electrodes crossing the WM of the TPJ, were analyzed to provide a functional correlate complementing the ex-vivo and in-vivo anatomical measures. The combination of diverse and multimodal observations allows to overcome the limitations intrinsic to single methodologies, and to define a unitary picture which makes it possible to investigate DL presurgically and at the individual patient level, so limiting the postsurgical damages. Notwithstanding, such a combined approach could serve as a model of investigation for successive neuroanatomical inquiries tackling WM fibers anatomy and function through SEEG-derived neurophysiological data.

\section{Materials And Methods}

Volume of interest identification and imaging visualization

The definition of the anatomical region, which was selected as the putative location of $D L$, was based on landmark cytological, histological, imaging works and atlases, defining OR positioning at the level of the 
TPJ (Burgel 1999; Mori 2005; Burgel 2006), following these steps:

1. visualization of the $\mathrm{OR}$ volumes, downloaded from the on-line Juelich Institute of Neuroscience and Medicine fiber tracts repository. These volumes have been produced by means of myelin-stained histological studies (Burgel 1999; Burgel 2006), and hereby visualized in a dedicated MNI-152 space (ICBM 2009c nonlinear symmetric);

2. given the need to define the volume of interest ( $\mathrm{VOI}$ ) related to $\mathrm{DL}$ in the context of the OR, the posterior thalamic radiation (PTR) label obtained from the JHU-ICBM-DTI-81 WM atlas (Mori 2005) was applied to the OR volumes, so that anterior, posterior, lateral and mesial limits of the DL volume were defined;

3. the inferior limit of the volume was chosen as the plane passing through the most anterior point of the calcarine fissure, parallel to that identified by the PTR label (Mori 2005), based on the segregation of OR fibers directed to the supra and infracalcarine cortices;

4. the superior limit identified by the histological studies was preserved (Burgel 1999; Burget 2006), to avoid the risk of undersampling the eventual most superior fibers of the DL (Figure 1).

Once the VOI was defined (Figure 1), the useful brain-MR volumetric sequences of each patient were registered to the dedicated $\mathrm{MNI}$ space. Each tractography and the anatomical reconstruction of the electrode contacts were visualized throughout the multimodal imaging integration workflow available in our Centre (Cardinale 2012).

Ex-vivo anatomical study

Cadaver dissections were authorized from the Ethical Committee of the APSS of Trento. Two human cerebral hemispheres (one left and one right) were prepared according to the modified Klingler's technique previously detailed (Sarubbo 2015). Microdissection was performed in April 2019 by a neurosurgeon (MR), with the supervision of two WM dissection experienced neurosurgeons (SS, ADB). Dissection started with the removal of both sulcal gray matter of the lateral aspect of the brain and U-fibers. Once the three components of the superior longitudinal fascicle have been detected, the posterior portion of the inferior fronto-occipital fascicle (IFOF), the inferior longitudinal fascicle, the OR and the tapetum were identified in a stepwise manner, from outside to inside (De Benedictis 2014). Grey matter at the tip of cuneus and lingual cortex was preserved according to a cortex-sparing technique (Martino 2011), to obtain the correct definition of the bundle and its terminations territories. Moreover, precuneus cortical structures were removed, helping the identification of fascicles connected only to the occipital cortex, helping the exclusion to those terminating also in the parietal cortex (i.e. IFOF). All the WM bundles covering the OR were removed, layer by layer, until the unambiguous identification of the OR, following a stepwise technique (Sarubbo 2015).

In vivo studies

Clinical data were obtained on our prospectively maintained database. All patients or their guardians gave their informed consent. The local Ethical Committee approved this study in 2020 (ID 348-24062020).

We selected those cases on which DL was supposed to be investigated by anatomical in-vivo studies (DTIbased tractography) or neurophysiological explorations (VEPs extracted from SEEG electrodes [Microdeep 
Intracerebral Electrodes-D08, Dixi Medical] following flash administration), excluding those patients with lesions (observed at the presurgical brain-MR) undermining the $\mathrm{OR}$ and/or those with clinical abnormalities involving the visual systems.

In particular, we considered all the patients who underwent SEEG at the "C. Munari" Epilepsy Surgery Centre, in Milan, between February 2017 and March 2021. SEEG is a methodology providing relevant information about seizure onset zone (SOZ) when the non-invasive analysis of anatomo-electro-clinical correlations does not allow a clear definition of it. SEEG is generally followed by SOZ intraprocedural radiofrequency thermocoagulation and/or resective surgery (Cardinale 2019).

The multimodal imaging, including tractography and the anatomical reconstruction of the electrodes contacts, was visualized throughout the imaging workflow integrated in our Centre (Cardinale 2012), once brain-MR volumetric sequences and post-processed datasets of each patient were registered to the dedicated MNI space.

\section{TRACTOGRAPHY}

All SEEG implanted patients underwent a preoperative work-out including dedicated brain-MR sequences (including DTI). MR datasets were acquired with a 1.5T Philips Achieva scanner, using a receive coil head SENSE 8 with 8 channels (Supplementary File). After DICOM to nifty image conversion, brain volumes were extracted from DTI and T1 images. The DTI volumes were then co-registered to the first volume acquired without gradients applied and corrected for noise reduction and eddy current algorithms using the specific tools of the FMRIB Software Library (FSL; http://fsl.fmrib.ox.ac.uk/fsl/fslwiki/). Fractional Anisotropy images and color maps indicating the principal diffusion directions (i.e. fiber orientations) were calculated from the DTI. DTI calculations and fiber tracking were performed with FSL-based FDT Diffusion toolkit, using probabilistic methods based on multiple regions-of-interest approach (ProbtrackX). OR tractography started with the definition of the seed-region of interest (ROI), drawn at the level of the lateral geniculate nucleus. Way-point ROIs were localized at the level of the green fibers (antero-posteriorly oriented) in the occipital cortex (Kamali 2014). Additional ROIs were considered, in case of local anatomical distortion, or fibers which are tracked outside the occipital lobe. The 3D structure of the OR was defined as the volume encompassed by the $10 \%$ of maximum value of output path distribution after being co-registered with the 3D reference sequence (i.e. volumetric T1). Each patient output path distribution was co-registered, through affine transformation (12 degree of freedom), to the dedicated MNI space, which was considered as the reference common space. A neurosurgeon with expertise in the field of advanced neuroimaging (MR) analyzed the position of the OR with as compared to the VOI volume. Tractography analysis was considered to be "positive" when at least a portion of the OR tractography lied in the VOI; on the other hand, if tractography did not lie at this level, it was considered as "negative".

For each hemisphere, a probability map was finally calculated summing up the binarized 3D OR structures of all the patients and dividing by the number of reconstructed tracts, in the dedicated MNI space. 
We selected patients whose implantations explored the VOI (Figure 1). For these patients, VEPs were collected during SEEG monitoring.

For each electrode targeting the VOI, we first identified all the contacts in the WM, thus excluding those directly recording from the cortex. This identification first relied on neuroimaging, i.e. the co-registration of post-implantation cone-beam computed tomography scan with the pre-implantation MR. Since co-registered imaging datasets suffer from accuracy limitation, the identification of the contacts localized in the WM was assisted by the analysis of the signal recorded in each contact (Greene et al., 2020)

Visual stimulation was performed routinely to identify the explored regions involved in the visual processing. Patients wear goggles, and receive 100 bilateral visual stimulations (i.e., flashes) at $1 \mathrm{~Hz}$, with an intensity of $3 \mathrm{~cd} / \mathrm{m}^{2}$. Visual evoked potentials are extracted for each channel as the average of the first 50 trials and of the last 50 trials in the time window $(0,200 \mathrm{~ms})$, following the stimulus delivery. Two electrophysiologists (IS, FMZ) blindly evaluated the traces for each electrode, and identified the contact presenting the earliest and most pronounced deflection.

To quantitatively assess the prevalence of phase-locking components in the identified channels relative to the neighbor territories, we further computed the inter-trial coherence (ITC) (Delorme and Makeig, 2004) for each of the identified channels, and compared statistically this variable against the channels located before and after the selected one. In other words, we evaluated the specificity of the identified features against the same signals recorded at $3.5 \mathrm{~mm}$ of distance along the electrode direction. ITC was computed in the interval $(0,200 \mathrm{~ms})$, and for frequencies ranging from 0 and $500 \mathrm{~Hz}$. Statistical comparison contrasting distribution of identified contacts against the adjacent one was performed via t-test ( $\mathrm{p}<0.01,1000$ permutation).

Once neurophysiological and tractography datasets have been separately and blindly analyzed, data were matched. In particular, each recording SEEG contact was labelled as intersecting, tangential or negative, according to its position relative to the reconstructed OR fibers. Intersecting were defined those contacts which lied, at least partially, within the reconstructed OR. Contacts were defined tangential if their minimum distance from OR was lower than $1.5 \mathrm{~mm}$. In the case of a greater distance, they were labeled as negative. To evaluate comparatively the performance of tractographic and electrophysiological assessments, we evaluated the convergence between the two sets of results, and in particular how many times the "relevant contacts" as identified by VEPs coincided with intersecting contacts as revealed by fiber tracking.

\section{Results}

Ex-vivo anatomical study

\section{ANTERIOR PORTION OF THE OR}

Insulo-opercular fibers, followed by the underlying external capsule and claustrum, were removed to highlight the most anterior course of the OR. Meyer's loop was clearly delineated in the rostral portion of the temporal WM, following the removal of the uncinate fasciculus (Figure 2, red pin, blue line). The uncinate 
fasciculus was identified thanks to its twisting shape connecting the anterior temporal and the frontal regions.

\section{MID-POSTERIOR PORTION OF THE OR}

Once the deepness of the Meyer's loop layer has been established, all fibers directed to the parietal region were removed, since they were supposed to belong to the IFOF, having a typical fanned distribution. After IFOF layer level identification, its occipital component of the IFOF was removed, with the delineation of the OR fibers. OR fibers coming from the anterior part of the bundle rise towards the bottom of precuneal region, followed by a mild slope to the occipital lobe and the calcarine fissure (Figure 2, green pin). The dissection allowed to visualize a "hump" at the most superior level of the OR, which can be considered as the DL, having a thickness of $2 \mathrm{~mm}$ (Figure 2, red pin, green line).

\section{TAPETUM}

Once moved to the mesial intraventricular side, at the level of atrium, the tapetum, whose fibers presented with a superior to inferior direction, was detected. Once distinguished from the OR (whose fibers are crossed to those of tapetum), tapetum thickness was measured, resulting $2 \mathrm{~mm}$.

In vivo studies

Between February 2017 and March 2021, we carried out 148 SEEG procedures on 147 patients (72 males and 75 females, with a median age of 29 years [IQR 21], at the time of brain-MR and SEEG study). Forty-one patients with a positive brain-MR along the OR course were excluded. Three of these 41 patients also suffered from a visual field defect documented by means of a computerized examination.

\section{TRACTOGRAPHY}

Unilateral or bilateral OR tractography was performed in 64 out of the remaining 106 patients (41 patients were excluded because OR was not drafted due to the SEEG planning pattern [i.e. not involving the OR course] and 1 patient was not included because DTI sequences were not acquired).

Fiber tracking resulted "positive" in the $86.7 \%$ of patients (58 patients). This sample included 24 males and 34 females, with a median age of 30.5 years (IQR 19.25) at the age of brain-MR and SEEG study. Tractography capability to intersect $\mathrm{DL}$, at sample level, was depicted through a probability map for each hemisphere (Figure 3).

\section{SEEG DATA RECORDING AND PROCESSING}

Following previous criteria, sixteen patients out of 106 (5M, 11F; median age 36.5 [IQR 23.75]) were selected as having an electrode exploring the VOI and SEEG recorded during a visual stimulation. Table 1 summarizes the demographic and clinical featutes for the examined population.

In all patients, VEP traces exhibited one contact recording from the WM (Figure 6; Supplementary Video 1 and 2), with a reliable burst of oscillations occurring by the first $100 \mathrm{~ms}$, and distinctive for a single channel 
(see Figure 4). The onset of this morphology was identified (see dotted lines in Figure 4), and values are reported in Table 2.

The comparison between the relevant contacts as identified via VEPs and the adjacent ones is reported in Figure 5. An increase of phase-locking was observed in both groups in the interval between 50 and $150 \mathrm{ms,}$ even if the values of ITC were stronger for the first group. More importantly, the statistical comparison underlined a significant interval in the time window between 20 and $40 \mathrm{~ms}$, indicating that relevant contacts have in this time period a phase-locking significantly higher than the adjacent contacts. Even from a spectral point of view, the significant interval lied between 50 and $100 \mathrm{~Hz}$, thus in a low-gamma frequency band.

Moving to the comparison between tractography and SEEG data, for 12 out of 15 patients (80\%) having complete data, the same contacts were identified blindly by the two procedures. In other words, the SEEG contacts presenting early high-frequency responses around $30 \mathrm{~ms}$ were labelled as intersecting the $\mathrm{OR}$ as reconstructed by the tractographic analysis. The procedures identified adjacent contacts in $2 / 15$, with an imprecision of about $3 \mathrm{~mm}$. Only one patient was problematic, as DTI-based reconstruction fell apart from the SEEG electrode, despite the positive identification of the VEP component. In summary, in 14/15 patients the identification was successful and convergent across the two modalities. The full details are reported in Table 2.

\section{Discussion}

From ex-vivo anatomical dissection to in-vivo structural and functional aspects

In the present study, we combined information from ex-vivo anatomy to the in-vivo structural and functional correlates of DL to provide new insights about its traceability in patients. Dissection by Klingler's technique is a consolidated and reliable approach to explore WM structure (Zemmoura 2016; De Benedictis 2012). Using this method, recent studies provided innovative insights about the course of both the inferior and superior components of $\mathrm{OR}$, and their spatial relationships with the other surrounding associative bundles (Parraga 2012; De Benedictis 2014; Sarubbo 2015; Koutsarnakis 2019). So far, a specific description of DL has never been reported, probably due to the challenging anatomical disambiguation from the IFOF. In fact, the posterior course of IFOF and OR shows a similar fanned and thin shape, intermingled in a densely packed anatomical region.

In the present study, we provided evidences that the "hump" in the deepest portion of the TPJ-WM corresponds to the DL (Figure 2). This finding is confirmed by the DTI-based tractography study, in which DL has been identified in more than $90 \%$ of the reconstructed ORs. As already shown by previous histological studies (Burgel 1999; Burgel 2006), although the superior OR bundle resulted more heterogenous than the inferior component (Figure 3), the method returned a reliable identification of the DL. Moreover, tractography data detailed the DL topography: fibers are grouped in the posterior portion of the VOI, in which they are supposed to convey before entering occipital territories (Figure 3). 
Neurophysiological VEPs investigation showed a surprisingly clear pattern for most of the analyzed electrodes. Indeed, within each (multi-contact) electrode, a single contact had a burst of high-frequency oscillations, phase-locked with the stimulus delivery, and distinct from the neighbor contacts (Figure 4). On average, we identified the onset of this EEG component at $30 \mathrm{~ms}$ (Table 2). To add a statistical comparison to this observation, we computed the ITC for all contacts exploring WM, contrasting the relevant contacts with the adjacent, non-relevant ones. Despite the variability of responses across patients, ITC was significant in a single time-frequency interval, i.e. between 20 and $40 \mathrm{~ms}$ in the gamma frequency band. This result corroborates the inspective report based on VEPs analysis, and points to an early time window as the one revealing whether a SEEG contact exploring WM is recording or not from the OR.

Specificity of visual-evoked early activity for a single contact within SEEG electrodes was indicative on the OR thickness at the level of DL. Indeed, in SEEG electrodes single contact width is $2 \mathrm{~mm}$, with contacts interspaced of $1.5 \mathrm{~mm}$ each other. Thus, if early VEPs component are observed on a single contact, we can hypothesize that the DL thickness is below $3.5 \mathrm{~mm}$. This conclusion is paralleled by both tractography results, displaying a mean thickness of $2.7 \mathrm{~mm}( \pm 0.9 \mathrm{~mm})$ in correspondence of the relevant SEEG contacts (see Table 2), and most importantly by results from ex-vivo dissections, indicating a DL thickness of $2 \mathrm{~mm}$.

The most important finding of our study is the convergence between SEEG and DTI-based data. Identification via fiber tracking of the SEEG contact crossing the OR coincided in 12 out of 15 patients with the relevant SEEG contacts identified solely via electrophysiology (see Figure 7 for the entire dataset relative to a single patient), and in 2 of the remaining patients the shift was minimal (see Table 2). This finding suggests that the DL can be monitored (and double-checked) in patients undergoing presurgical investigations, from both anatomical and electrophysiological point of views, returning a coherent picture. We noticed a mismatch between neurophysiological data and fiber tracking in only few cases. This aspect involves both $\mathrm{DL}$ detection and its thickness and could be due to the tractography accuracy limitations (Schilling 2019; Zhu 2012), which become particularly evident for thin and highly curved tracts located in a densely packed WM region. The relatively thin thickness of $2 \mathrm{~mm}$, the high curvature at the level of $D L$ and the high density of the investigated WM volume could then explain the small shift between fiber tracking and SEEG results in the $20 \%$ of our patient sample. In addition, the abovementioned obstacles may lead to a relaxation of the parameters employed for tractography reconstruction, and ultimately to an excess of fiber tracking false positives and inflated fiber thickness. Despite some high value, the average thickness returned by tractography is similar to that derived from ex-vivo procedures, suggesting a small impact of false positives in our analysis.

In summary, we proved that location and thickness of DL can be traced in-vivo by means of fiber tracking (Figure 3), and that these observations parallel the electrophysiological responses to visual stimulations as recorded by SEEG (Figure 6). This latter aspect proposes the DL as the WM substrate explaining the visual deficits often experienced by patients undergoing resective surgery involving TPJ, and opens to the development of new presurgical or intraoperative procedures.

\section{Clinical and surgical considerations}


Previous reports of the surgical approach to the TPJ region were focused on the issue of cortical and subcortical language structures sparing (Maldonado 2011; Rolland 2018), with a secondary focus on optic radiation damage risk. As a consequence of this study, we underline that surgical planning for TPJ resections has to consider the risk of damaging those fibers conveying information from the contralateral inferior quadrant. This aspect is of particular value in case of a resection with oncological purposes, but also in the field of epilepsy surgery, in which resection involves only cortical structures, but WM risks to be damaged due to vessels coagulation, rupture or manipulation. A similar scenario is observed in the posterior insular surgery, with indirect damage to the adjacent cortico-spinal tract (Delion 2014).

Given these observations, different strategies may be indicated to minimize the risk of DL damage, as the following:

- to be aware of the complex TPJ-WM architecture, including the actual position of the DL. This awareness has to be clear also during the preoperative discussion of the case with the patient, and during surgical planning;

- to prepare an imaging-based WM representation of the whole OR (tractography) to be considered either for the presurgical planning and the intraoperative navigation (Costabile 2019). This study allows to display and quantify the accuracy of tractography in DL identification, with a specific methodology;

- to consider the use of electrophysiological monitoring to evaluate the presence of early components in response to visual stimulations. Intriguingly, such a procedure can be applied both in presurgical monitoring (e.g. SEEG), and potentially also in intraoperative procedures;

- to train by cadaver dissection, in order to mentalize the spatial relationship between anatomical structures, including both gray and white matters (Gnanakumar 2018).

\section{SEEG for the study of WM}

In the present study, we took advantage of SEEG recordings to provide a neurophysiological counterpart to the tractography and anatomical observation concerning the DL-OR. As discussed in a previous paper (Avanzini et al., 2016), intraparenchymal recordings present lots of advantages also relative to ECOG, spanning from an extensive and more distributed sampling of the cortical sheet, to the minimal or absent volume conduction issues. Beyond these aspects, it is worth noting that about the $30-40 \%$ of SEEG recording contacts explore the WM (Avanzini et al, 2018), and while these signals are used typically to create a virtually null reference (Cardinale et al, 2019), their EEG activity is often discarded as an activity of noninterest, especially if compared with the richer and more complex activity recorded from the cortex. We believe that this large amount of data provides a valuable information to describe the anatomical and functional correlates of several WM bundles. Given their coherence with tractography and anatomical data, these studies would contribute to characterize the human connectome with a innovative source of information, complementing the neuroimaging techniques with a four-dimensional, time-dependent characterization of WM structures.

\section{Abbreviations}




$$
\begin{aligned}
& \mathrm{DL}=\text { dorsal loop } \\
& \mathrm{DTI}=\text { diffusion tensor imaging } \\
& \mathrm{ID}=\text { identification } \\
& \mathrm{IFOF} \text { = inferior fronto-occipital fasciculus } \\
& \mathrm{ITC}=\text { inter-trial coherence } \\
& \text { LGN = lateral geniculate nucleus } \\
& \text { MR = magnetic resonance } \\
& \mathrm{OR}=\text { optic radiation } \\
& \text { ROI = region of interest } \\
& \text { SEEG = stereoelectroencefalography } \\
& \text { TPJ = temporo-parietal junction } \\
& \text { VEP = visual evoked potential } \\
& \text { VOI = volume of interest } \\
& \text { WM = white matter } \\
& \text { Declarations }
\end{aligned}
$$

\section{Declarations}

Funding: MDV was supported by European Union Horizon 2020 Framework Program through Grant Agreement No. 935539 (Human Brain Project, SGA3) to PA.

Conflict of interest/competing interest: Michele Rizzi recently resulted consultant for WISE srl, a manufacturer of implantable leads for neuromodulation and neuromonitoring.

Availability of data and material: data will be made available upon reasonable request.

Code availability: not applicable.

Authors' contribution: Michele Rizzi conceived and designed the analysis, collected the data, performed the analysis and wrote the paper; Khalid Al-Orabi collected the data and critically revised the paper; Pietro Avanzini conceived and designed the analysis, performed the analysis and wrote the paper; Luca Berta collected the data and performed the analysis; Alessandro De Benedictis collected the data and critically revised the paper; Maria Del Vecchio performed the analysis and wrote the paper; Domenico Lizio collected the data and performed the analysis; Valeria Mariani collected the data, performed the analysis and critically revised the paper; Ivana Sartori conceived and designed the analysis, collected the data, performed the 
analysis and wrote the paper; Silvio Sarubbo collected the data and critically revised the paper; Flavia Zauli collected the data and critically revised the paper.

Ethics approval: approval number of the local ethical committee: ID 348-24062020.

Consent to participate: not applicable.

\section{ACKNOWLEDGMENTS}

We thank all the colleagues of the "C.Munari" Group for the suggestions during the stages of the study.

\section{References}

1. Avanzini P, Abdollahi RO, Sartori I, Caruana F, Pelliccia V, Casaceli G, Mai R, Lo Russo G, Rizzolatti G, Orban GA. Four-dimensional maps of the human somatosensory system. Proc Natl Acad Sci U S A. 2016 Mar 29;113(13):E1936-43. doi: 10.1073/pnas.1601889113.

2. Avanzini P, Pelliccia V, Lo Russo G, Orban GA, Rizzolatti G. Multiple time courses of somatosensory responses in human cortex. Neuroimage. 2018 Apr 1;169:212-226. doi: 10.1016/j.neuroimage.2017.12.037.

3. Bürgel U, Schormann T, Schleicher A, Zilles K. Mapping of histologically identified long fiber tracts in human cerebral hemispheres to the MRI volume of a reference brain: position and spatial variability of the optic radiation. Neuroimage. 1999 Nov;10(5):489 - 99. doi: 10.1006/nimg.1999.0497.

4. Bürgel U, Amunts K, Hoemke L, Mohlberg H, Gilsbach JM, Zilles K. White matter fiber tracts of the human brain: three-dimensional mapping at microscopic resolution, topography and intersubject variability. Neuroimage. 2006 Feb 15;29(4):1092 - 105. doi: 10.1016/j.neuroimage.2005.08.040.

5. Cardinale F, Miserocchi A, Moscato A, Cossu M, Castana L, Schiariti M, Gozzo F, Pero G, Quilici L, Citterio A, Minella M, Torresin A, Lo Russo G: Talairach methodology in the multimodal imaging and robotic era. In Scarabin JM ed. Stereotaxy and Epilepsy Neurosurgery. John Libbey Eurotext Editions: pp. 245$271 ; 2012$

6. Cardinale F, Rizzi M, Vignati E, Cossu M, Castana L, d'Orio P, Revay M, Costanza MD, Tassi L, Mai R, Sartori I, Nobili L, Gozzo F, Pelliccia V, Mariani V, Lo Russo G, Francione S.

Stereoelectroencephalography: retrospective analysis of 742 procedures in a single centre. Brain. 2019 Sep 1;142(9):2688-2704. doi: 10.1093/brain/awz196.

7. Catani M, Robertsson N, Beyh A, Huynh V, de Santiago Requejo F, Howells H, Barrett RLC, Aiello M, Cavaliere C, Dyrby TB, Krug K, Ptito M, D'Arceuil H, Forkel SJ, Dell'Acqua F. Short parietal lobe connections of the human and monkey brain. Cortex. 2017 Dec;97:339-357. doi: 10.1016/j.cortex.2017.10.022.

8. Cheng HC, Guo CY, Chen MJ, Ko YC, Huang N, Liu CJ. Patient-reported vision-related quality of life differences between superior and inferior hemifield visual field defects in primary open-angle glaucoma. JAMA Ophthalmol. 2015 Mar;133(3):269 - 75. doi: 10.1001/jamaophthalmol.2014.4908. 
9. Costabile JD, Alaswad E, D'Souza S, Thompson JA, Ormond DR. Current Applications of Diffusion Tensor Imaging and Tractography in Intracranial Tumor Resection. Front Oncol. 2019 May 29;9:426. doi: 10.3389/fonc.2019.00426.

10. De Benedictis A, Duffau H, Paradiso B, Grandi E, Balbi S, Granieri E, Colarusso E, Chioffi F, Marras CE, Sarubbo S. Anatomo-functional study of the temporo-parieto-occipital region: dissection, tractographic and brain mapping evidence from a neurosurgical perspective. J Anat. 2014 Aug;225(2):132 - 51. doi: 10.1111/joa.12204.

11. De Benedictis A, Sarubbo S, Duffau H. Subcortical surgical anatomy of the lateral frontal region: human white matter dissection and correlations with functional insights provided by intraoperative direct brain stimulation: laboratory investigation. J Neurosurg. 2012 Dec;117(6):1053-69. doi: 10.3171/2012.7.JNS12628.

12. Delion M, Mercier P. Microanatomical study of the insular perforating arteries. Acta Neurochir (Wien). 2014 Oct;156(10):1991-7; discussion 1997-8. doi: 10.1007/s00701-014-2167-9.

13. Delorme A, Makeig S. EEGLAB: an open source toolbox for analysis of single-trial EEG dynamics including independent component analysis. J Neurosci Methods. 2004 Mar 15;134(1):9-21. doi: 10.1016/j.jneumeth.2003.10.009.

14. Ebeling U, Reulen HJ. Neurosurgical topography of the optic radiation in the temporal lobe. Acta Neurochir (Wien). 1988;92(1-4):29-36. doi: 10.1007/BF01401969.

15. Fan X, Roberts DW, Kamal Y, Olson JD, Paulsen KD. Quantification of Subdural Electrode Shift Between Initial Implantation, Postimplantation Computed Tomography, and Subsequent Resection Surgery. Oper Neurosurg (Hagerstown). 2019 Jan 1;16(1):9-19. doi: 10.1093/ons/opy050.

16. Gnanakumar S, Kostusiak M, Budohoski KP, Barone D, Pizzuti V, Kirollos R, Santarius T, Trivedi R. Effectiveness of Cadaveric Simulation in Neurosurgical Training: A Review of the Literature. World Neurosurg. 2018 Oct;118:88-96. doi: 10.1016/j.wneu.2018.07.015.

17. Greene P, Li A, González-Martínez J, Sarma SV. Classification of Stereo-EEG Contacts in White Matter vs. Gray Matter Using Recorded Activity. Front Neurol. 2021 Jan 6;11:605696. doi: 10.3389/fneur.2020.605696.

18. Kamali A, Hasan KM, Adapa P, Razmandi A, Keser Z, Lincoln J, Kramer LA. Distinguishing and quantification of the human visual pathways using high-spatial-resolution diffusion tensor tractography. Magn Reson Imaging. 2014 Sep;32(7):796-803. doi: 10.1016/j.mri.2014.04.002.

19. Koutsarnakis C, Kalyvas AV, Komaitis S, Liakos F, Skandalakis GP, Anagnostopoulos C, Stranjalis G. Defining the relationship of the optic radiation to the roof and floor of the ventricular atrium: a focused microanatomical study. J Neurosurg. 2018 May 4:1-12. doi: 10.3171/2017.10.JNS171836.

20. Lilja Y, Nilsson DT. Strengths and limitations of tractography methods to identify the optic radiation for epilepsy surgery. Quant Imaging Med Surg. 2015 Apr;5(2):288 - 99. doi: 10.3978/j.issn.22234292.2015.01.08.

21. Maldonado IL, Moritz-Gasser S, de Champfleur NM, Bertram L, Moulinié G, Duffau H. Surgery for gliomas involving the left inferior parietal lobule: new insights into the functional anatomy provided by 
stimulation mapping in awake patients. J Neurosurg. 2011 Oct;115(4):770-9. doi:

10.3171/2011.5.JNS112.

22. Mandelstam SA. Challenges of the anatomy and diffusion tensor tractography of the Meyer loop. AJNR Am J Neuroradiol. 2012 Aug;33(7):1204-10. doi: 10.3174/ajnr.A2652.

23. Mandonnet E, Cerliani L, Siuda-Krzywicka K, Poisson I, Zhi N, Volle E, de Schotten MT. A network-level approach of cognitive flexibility impairment after surgery of a right temporo-parietal glioma. Neurochirurgie. 2017 Sep;63(4):308-313. doi: 10.1016/j.neuchi.2017.03.003.

24. Martino J, De Witt Hamer PC, Vergani F, Brogna C, de Lucas EM, Vázquez-Barquero A, García-Porrero JA, Duffau $\mathrm{H}$. Cortex-sparing fiber dissection: an improved method for the study of white matter anatomy in the human brain. J Anat. 2011 Oct;219(4):531 - 41. doi: 10.1111/j.1469-7580.2011.01414.x.

25. Martino J, da Silva-Freitas R, Caballero H, Marco de Lucas E, García-Porrero JA, Vázquez-Barquero A. Fiber dissection and diffusion tensor imaging tractography study of the temporoparietal fiber intersection area. Neurosurgery. 2013 Mar;72(1 Suppl Operative):87-97; discussion 97 - 8. doi: 10.1227/NEU.0b013e318274294b.

26. Meyer A. The connections of the occipital lobes and the present status of the cerebral visual affections. Trans Assoc Am Physicians 1907; 22:7-16.

27. Mori $S$ and Crain BJ. MRI atlas of human white matter. Amsterdam: Elsevier. 2005

28. Nowell M, Vos SB, Sidhu M, Wilcoxen K, Sargsyan N, Ourselin S, Duncan JS. Meyer's loop asymmetry and language lateralisation in epilepsy. J Neurol Neurosurg Psychiatry. 2016 Aug;87(8):836 - 42. doi: 10.1136/jnnp-2015-311161.

29. Párraga RG, Ribas GC, Welling LC, Alves RV, de Oliveira E. Microsurgical anatomy of the optic radiation and related fibers in 3-dimensional images. Neurosurgery. 2012 Sep;71(1 Suppl Operative):160 - 71; discussion 171-2. doi: 10.1227/NEU.0b013e3182556fde.

30. Piper RJ, Yoong MM, Kandasamy J, Chin RF. Application of diffusion tensor imaging and tractography of the optic radiation in anterior temporal lobe resection for epilepsy: a systematic review. Clin Neurol Neurosurg. 2014 Sep;124:59-65. doi: 10.1016/j.clineuro.2014.06.013.

31. Platonov A, Avanzini P, Pelliccia V, LoRusso G, Sartori I, Orban GA. Rapid and specific processing of person-related information in human anterior temporal lobe. Commun Biol. 2019 Jan 4;2:5. doi: 10.1038/s42003-018-0250-0.

32. Rolland A, Herbet G, Duffau H. Awake Surgery for Gliomas within the Right Inferior Parietal Lobule: New Insights into the Functional Connectivity Gained from Stimulation Mapping and Surgical Implications. World Neurosurg. 2018 Apr;112:e393-e406. doi: 10.1016/j.wneu.2018.01.053.

33. Sanai N, Martino J, Berger MS. Morbidity profile following aggressive resection of parietal lobe gliomas. J Neurosurg. 2012 Jun;116(6):1182-6. doi: 10.3171/2012.2.JNS111228.

34. Sarubbo S, De Benedictis A, Milani P, Paradiso B, Barbareschi M, Rozzanigo U, Colarusso E, Tugnoli V, Farneti M, Granieri E, Duffau H, Chioffi F. The course and the anatomo-functional relationships of the optic radiation: a combined study with 'post mortem' dissections and 'in vivo' direct electrical mapping. J Anat. 2015 Jan;226(1):47-59. doi: 10.1111/joa.12254. 
35. Schilling KG, Daducci A, Maier-Hein K, Poupon C, Houde JC, Nath V, Anderson AW, Landman BA, Descoteaux M. Challenges in diffusion MRI tractography - Lessons learned from international benchmark competitions. Magn Reson Imaging. 2019 Apr;57:194-209. doi: 10.1016/j.mri.2018.11.014.

36. Taoka T, Sakamoto M, Nakagawa H, Nakase H, Iwasaki S, Takayama K, Taoka K, Hoshida T, Sakaki T, Kichikawa K. Diffusion tensor tractography of the Meyer loop in cases of temporal lobe resection for temporal lobe epilepsy: correlation between postsurgical visual field defect and anterior limit of Meyer loop on tractography. AJNR Am J Neuroradiol. 2008 Aug;29(7):1329-34. doi: 10.3174/ajnr.A1101.

37. Wu Y, Sun $D$, Wang $Y$, Wang $Y$, Wang Y. Tracing short connections of the temporo-parieto-occipital region in the human brain using diffusion spectrum imaging and fiber dissection. Brain Res. 2016 Sep 1;1646:152-159. doi: 10.1016/j.brainres.2016.05.046

38. Yu HH, Atapour N, Chaplin TA, Worthy KH, Rosa MGP. Robust Visual Responses and Normal Retinotopy in Primate Lateral Geniculate Nucleus following Long-term Lesions of Striate Cortex. J Neurosci. 2018 Apr 18;38(16):3955-3970. doi: 10.1523/JNEUROSCI.0188-18.2018.

39. Zemmoura I, Blanchard E, Raynal PI, Rousselot-Denis C, Destrieux C, Velut S. How Klingler's dissection permits exploration of brain structural connectivity? An electron microscopy study of human white matter. Brain Struct Funct. 2016 Jun;221(5):2477-86. doi: 10.1007/s00429-015-1050-7.

40. Zhu FP, Wu JS, Song YY, Yao CJ, Zhuang DX, Xu G, Tang WJ, Qin ZY, Mao Y, Zhou LF. Clinical application of motor pathway mapping using diffusion tensor imaging tractography and intraoperative direct subcortical stimulation in cerebral glioma surgery: a prospective cohort study. Neurosurgery. 2012 Dec;71(6):1170-83; discussion 1183-4.

\section{Tables}

Table 1: demographics of SEEG patients selected for neurophysiological analysis (FCD $=$ focal cortical dysplasia; RF-THC = radiofrequency thermocoagulation) 


\begin{tabular}{|c|c|c|c|c|c|c|c|}
\hline $\begin{array}{l}\mathrm{Pt} \text { ID } \\
\text { number }\end{array}$ & Sex & $\begin{array}{l}\text { Epilepsy } \\
\text { duration } \\
\text { (years) }\end{array}$ & $\begin{array}{l}\text { Age } \\
\text { at } \\
\text { MR } \\
\text { and } \\
\text { SEEG }\end{array}$ & $\begin{array}{l}\text { Brain-MR } \\
\text { (at OR level) }\end{array}$ & Etiology & $\begin{array}{l}\text { Neurological } \\
\text { examination }\end{array}$ & Histopathology \\
\hline 1 & $M$ & 18 & 46 & negative & unknown & negative & gliosis \\
\hline 2 & $M$ & 6 & 20 & negative & unknown & negative & gliosis \\
\hline 3 & $\mathrm{~F}$ & 11 & 14 & negative & malformative & negative & gliosis \\
\hline 4 & $\mathrm{~F}$ & 13 & 21 & $\begin{array}{l}\text { bilateral } \\
\text { hippocampal } \\
\text { abnormal } \\
\text { gyration }\end{array}$ & $\begin{array}{l}\text { unexpected } \\
\text { preterm } \\
\text { delivery }\end{array}$ & negative & $\begin{array}{l}\text { anterior } \\
\text { temporal FCD } \\
\text { la }\end{array}$ \\
\hline 5 & $\mathrm{~F}$ & 29 & 38 & negative & unknown & negative & gliosis \\
\hline 6 & $\mathrm{~F}$ & 30 & 37 & negative & unknown & negative & parietal FCD Ila \\
\hline 7 & $\mathrm{~F}$ & 5 & 16 & negative & unknown & negative & gliosis \\
\hline 8 & $\mathrm{~F}$ & 39 & 43 & negative & unknown & negative & gliosis \\
\hline 9 & $\mathrm{~F}$ & 8 & 14 & negative & malformative & negative & insular FCD Ila \\
\hline 10 & $\mathrm{~F}$ & 18 & 39 & negative & unknown & negative & $\begin{array}{l}\text { no surgery, RF- } \\
\text { THC only }\end{array}$ \\
\hline 11 & $\mathrm{~F}$ & 3 & 12 & negative & unknown & negative & $\begin{array}{l}\text { posterior } \\
\text { temporal FCD } \\
\text { lb }\end{array}$ \\
\hline 12 & $M$ & 43 & 44 & negative & post-vaccine & negative & $\begin{array}{l}\text { no surgery, RF- } \\
\text { THC only }\end{array}$ \\
\hline 13 & $M$ & 18 & 39 & negative & post-infective & negative & $\begin{array}{l}\text { no surgery, RF- } \\
\text { THC only }\end{array}$ \\
\hline 14 & $\mathrm{~F}$ & 20 & 39 & negative & unknown & negative & $\begin{array}{l}\text { no surgery, RF- } \\
\text { THC only }\end{array}$ \\
\hline 15 & $M$ & 6 & 15 & negative & unknown & negative & gliosis \\
\hline 16 & $\mathrm{~F}$ & 21 & 36 & $\begin{array}{l}\text { left basal } \\
\text { temporo- } \\
\text { occipital } \\
\text { malformation }\end{array}$ & malformative & negative & $\begin{array}{l}\text { no surgery, RF- } \\
\text { THC only }\end{array}$ \\
\hline
\end{tabular}

Table 2: details of neurophysiological and tractographical analysis 


\begin{tabular}{|c|c|c|c|c|c|c|c|}
\hline $\begin{array}{l}\text { Pt ID } \\
\text { number }\end{array}$ & $\begin{array}{l}\text { Side of } \\
\text { considered } \\
\text { contact }\end{array}$ & $\begin{array}{l}\text { Electrode } \\
\text { name }\end{array}$ & $\begin{array}{l}\text { White } \\
\text { matter } \\
\text { contacts }\end{array}$ & $\begin{array}{l}\text { Relevant } \\
\text { contact }\end{array}$ & $\begin{array}{l}\text { Latency } \\
\text { (ms) }\end{array}$ & $\begin{array}{l}\text { Relationship } \\
\text { between OR } \\
\text { tractography and } \\
\text { local contacts } \\
\text { ("relevant" and } \\
\text { adjacents) }\end{array}$ & $\begin{array}{l}\text { OR } \\
\text { thickness } \\
\text { at the } \\
\text { local } \\
\text { contacts } \\
\text { (mm) }\end{array}$ \\
\hline 1 & $\mathrm{R}$ & $Y$ & $4-11$ & 9 & 36.8 & $\begin{array}{l}\text { dwi images not } \\
\text { acquired }\end{array}$ & \\
\hline 2 & $\mathrm{R}$ & Z & $7-10$ & 8 & 33 & $7 N-8 T-9 T$ & 1.7 \\
\hline 3 & L & $W^{\prime}$ & $5-9$ & 8 & 25.5 & $7 T-8 \mathbf{I}-9 \mathrm{~T}$ & 3 \\
\hline 4 & $\mathrm{R}$ & Q & $8-11$ & 9 & 33.6 & $8 N-9 I-10 T$ & 2.7 \\
\hline 5 & $\mathrm{R}$ & $x$ & $4-10$ & 7 & 25.5 & negative & \\
\hline 6 & $\mathrm{R}$ & Y & $6-7$ & 6 & 32 & $6 I-7 T$ & 4.2 \\
\hline 7 & $\mathrm{R}$ & $Y$ & 6-11 & 9 & 32.6 & $8 I-9 I-10 T$ & 4.5 \\
\hline 8 & L & $Z^{\prime}$ & 7-10 & 8 & 34.4 & $7 N-8 T-9 l$ & 1.9 \\
\hline 9 & $\mathrm{R}$ & $Y$ & $5-10$ & 8 & 22.6 & $7 \mathrm{~T}-\mathbf{8 I}-9 \mathrm{~T}$ & 3.7 \\
\hline 10 & L & $K^{\prime}$ & $6-10$ & 9 & 27.3 & $8 I-9 I-10 N$ & 2.6 \\
\hline 11 & $\mathrm{R}$ & $J$ & $8-9$ & 8 & 30.8 & $8 T-91$ & 2.8 \\
\hline 12 & $\mathrm{R}$ & Y & 8-10 & 9 & 24.5 & $8 T-9 I-10 T$ & 2.1 \\
\hline 13 & L & $X^{\prime}$ & 7-10 & 9 & 27.3 & $8 T-9 I-10 T$ & 2.7 \\
\hline 14 & L & $Y^{\prime}$ & $4-10$ & 9 & 28.8 & $8 N-9 I-10 T$ & 3.5 \\
\hline 15 & L & $Q^{\prime}$ & $5-10$ & 9 & 28.5 & $8 \mathrm{~T}-9 \mathrm{I}-10 \mathrm{~N}$ & 1.3 \\
\hline \multirow[t]{3}{*}{16} & L & $P^{\prime}$ & $4-10$ & 6 & 32.4 & $5 T-6 T-7 N$ & 2 \\
\hline & & & & & $\begin{array}{l}\text { mean } \\
(+/-D S) \\
29.7\end{array}$ & & $\begin{array}{l}\text { mean } \\
(+/-D S) \\
2.7\end{array}$ \\
\hline & & & & & $\begin{array}{l}(+/- \\
3.9)\end{array}$ & & $(+/-0.9)$ \\
\hline
\end{tabular}

Figures 


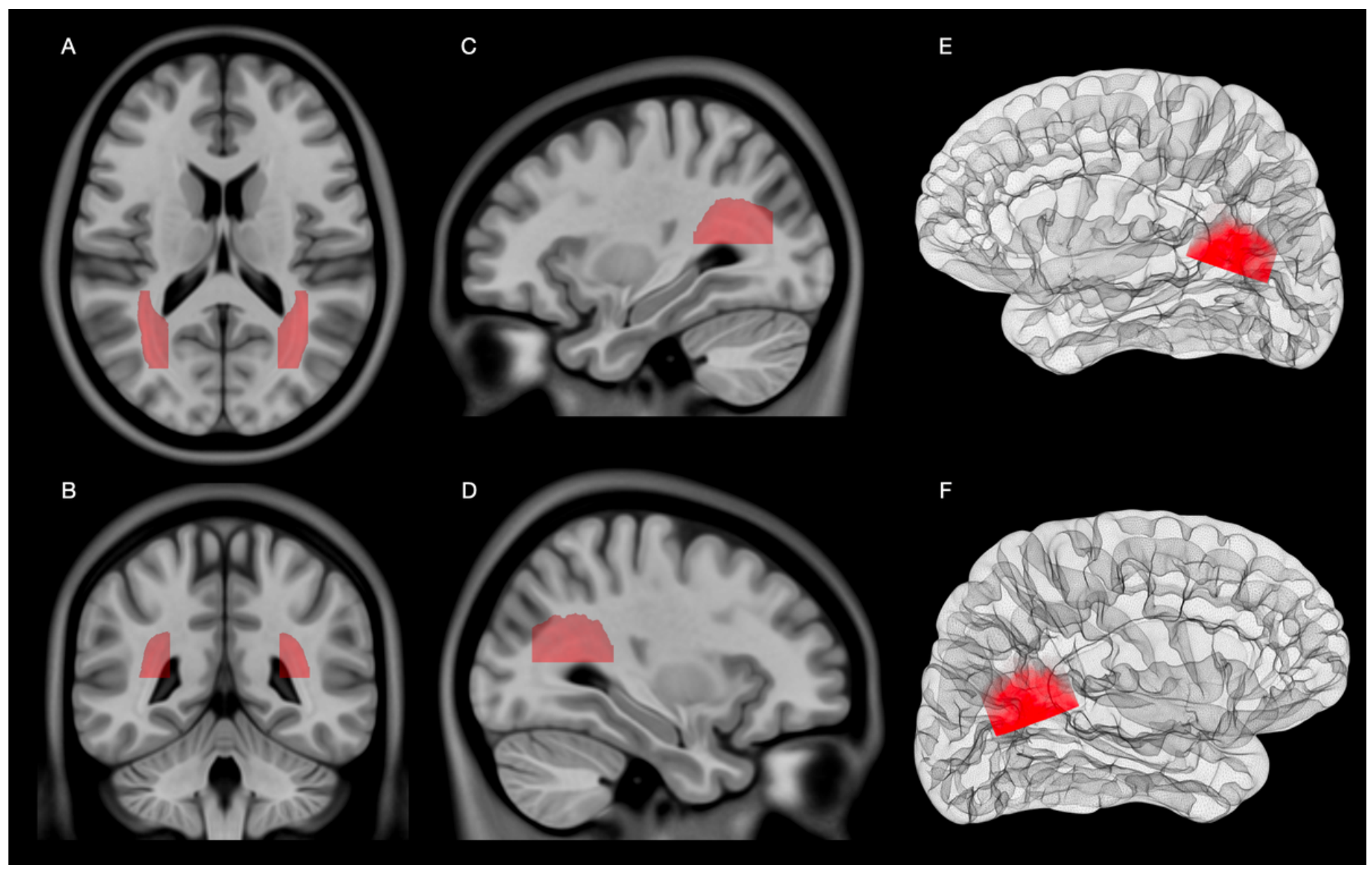

\section{Figure 1}

Definition of VOI topography. Bilateral representation of the VOI rendering (in red) topography in the dedicated T1 MNI-space with multiplanar view (A-D) and 3D reconstructions (E-F). 


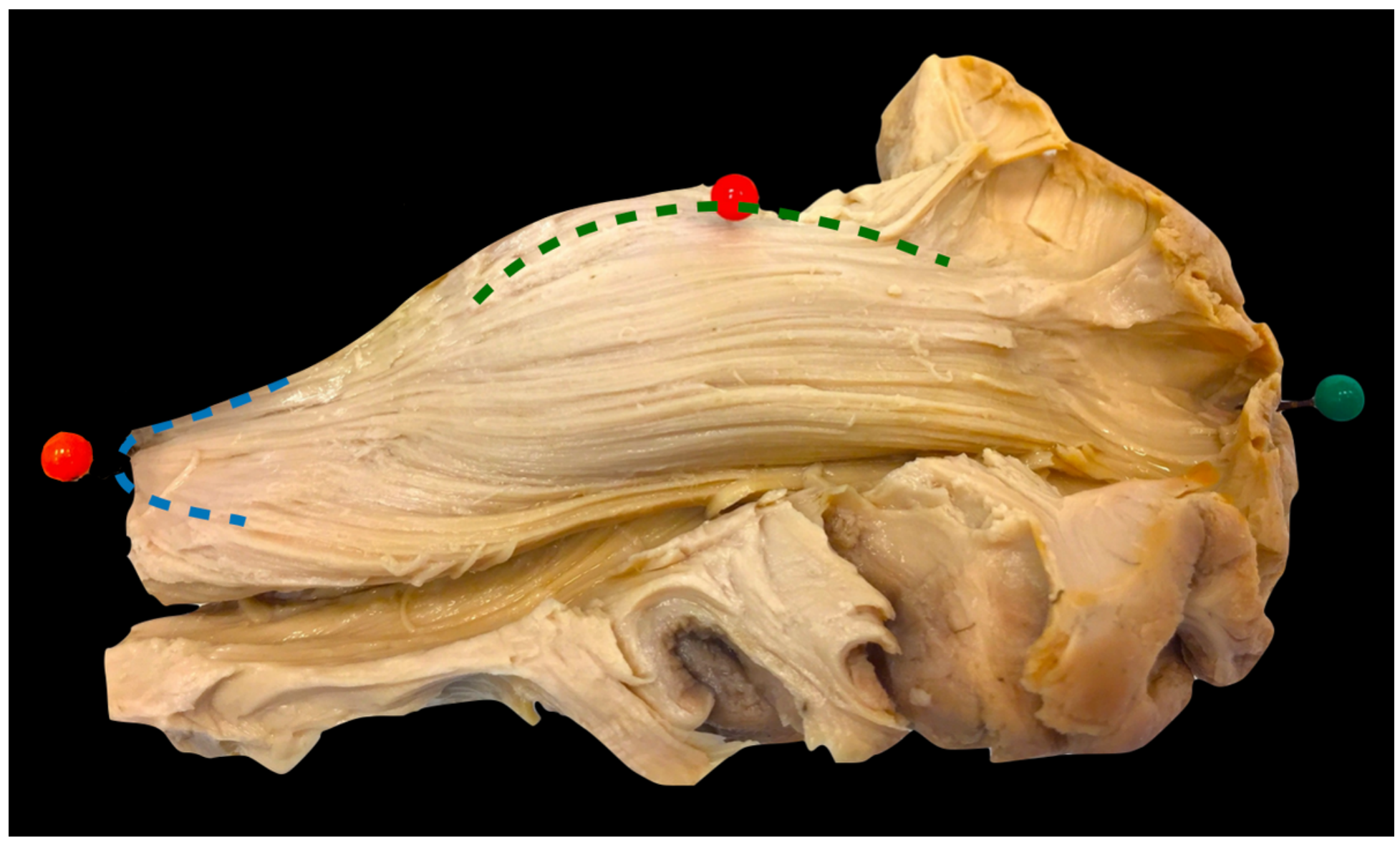

\section{Figure 2}

OR cadaver dissection. Left-side OR dissection illustration: red pin with blue line refers to the anterior portion of Meyer's loop; red pin with green line refers to the DL; green pin identifies the level of the calcarine fissure. 

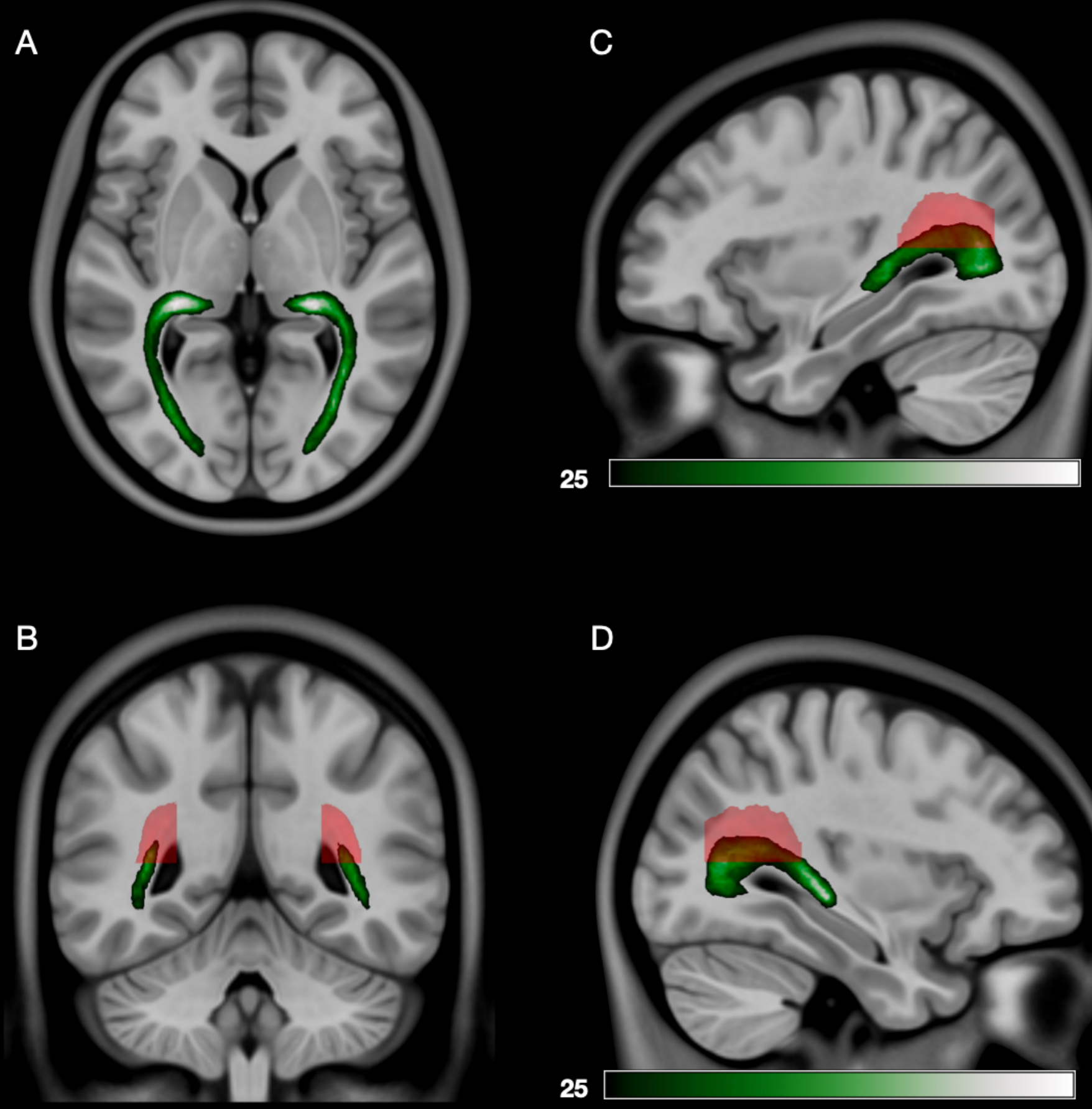

D

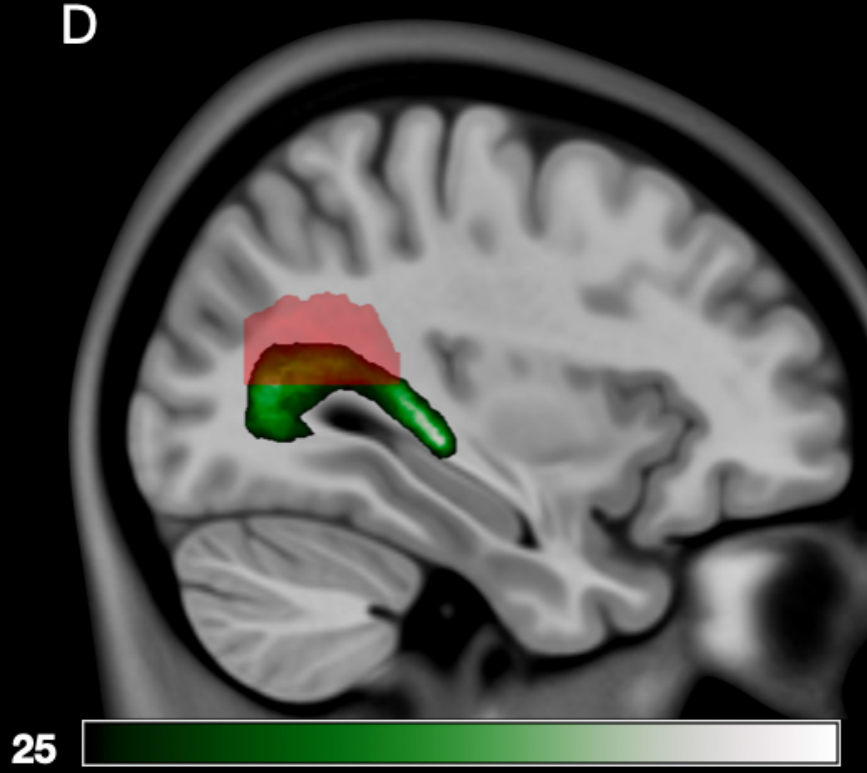

\section{Figure 3}

OR tractography probability maps. Probability maps of ORs tractography (green to white) have been represented bilaterally, using multiple planes (A-D) with bilateral VOI rendering superimposed (red). Color bars (related to the figure $C$ and $D$ ) represents the statistical dispersion (inter-quartile range). 


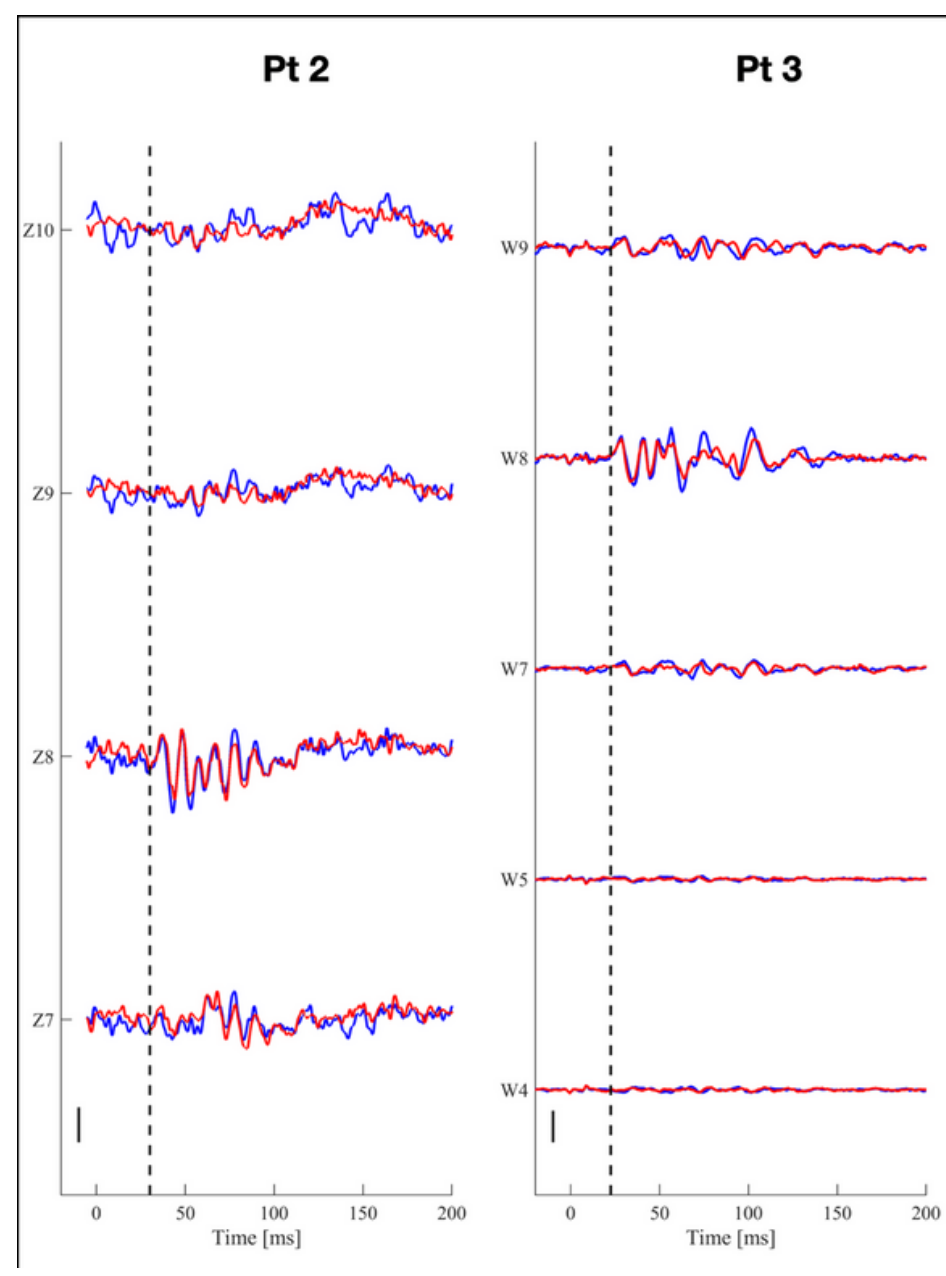

Pt 7

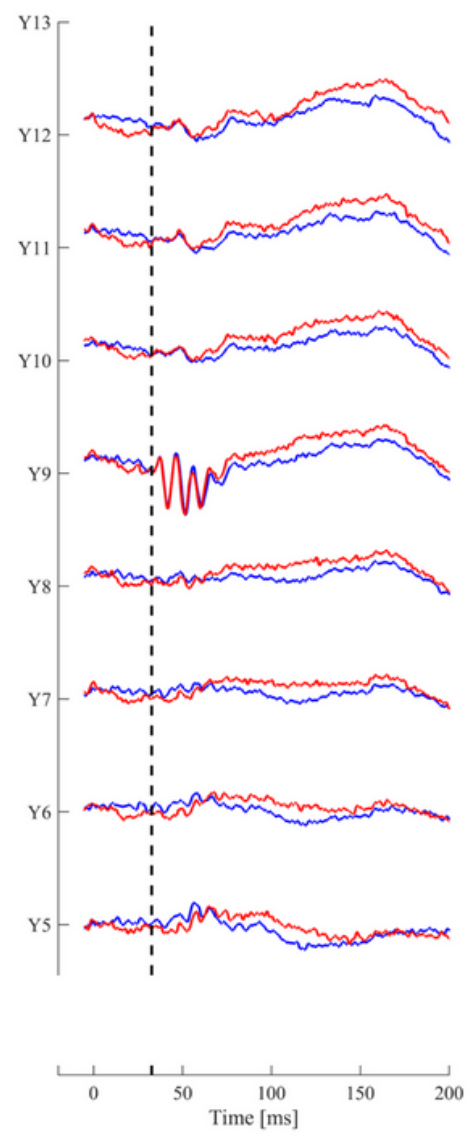

Pt 9

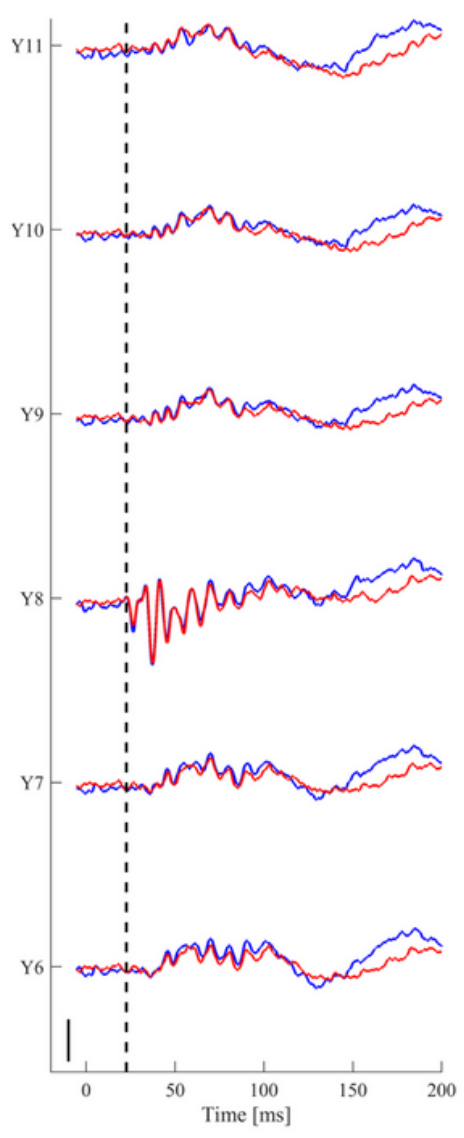

Figure 4

Visual-Evoked Potential in white matter contacts in the VOI. It shows for four representative patients the VEP traces for contacts exploring the white matters in the VOI (see Methods for data filtering). For all patients, only one contact (further referred as election contact) exhibits a peculiar and reliable burst of oscillations occurring within 100 ms after the stimulus delivery. Latencies values following inspection of VEPs morphology are reported in Table 2 for all patients. 

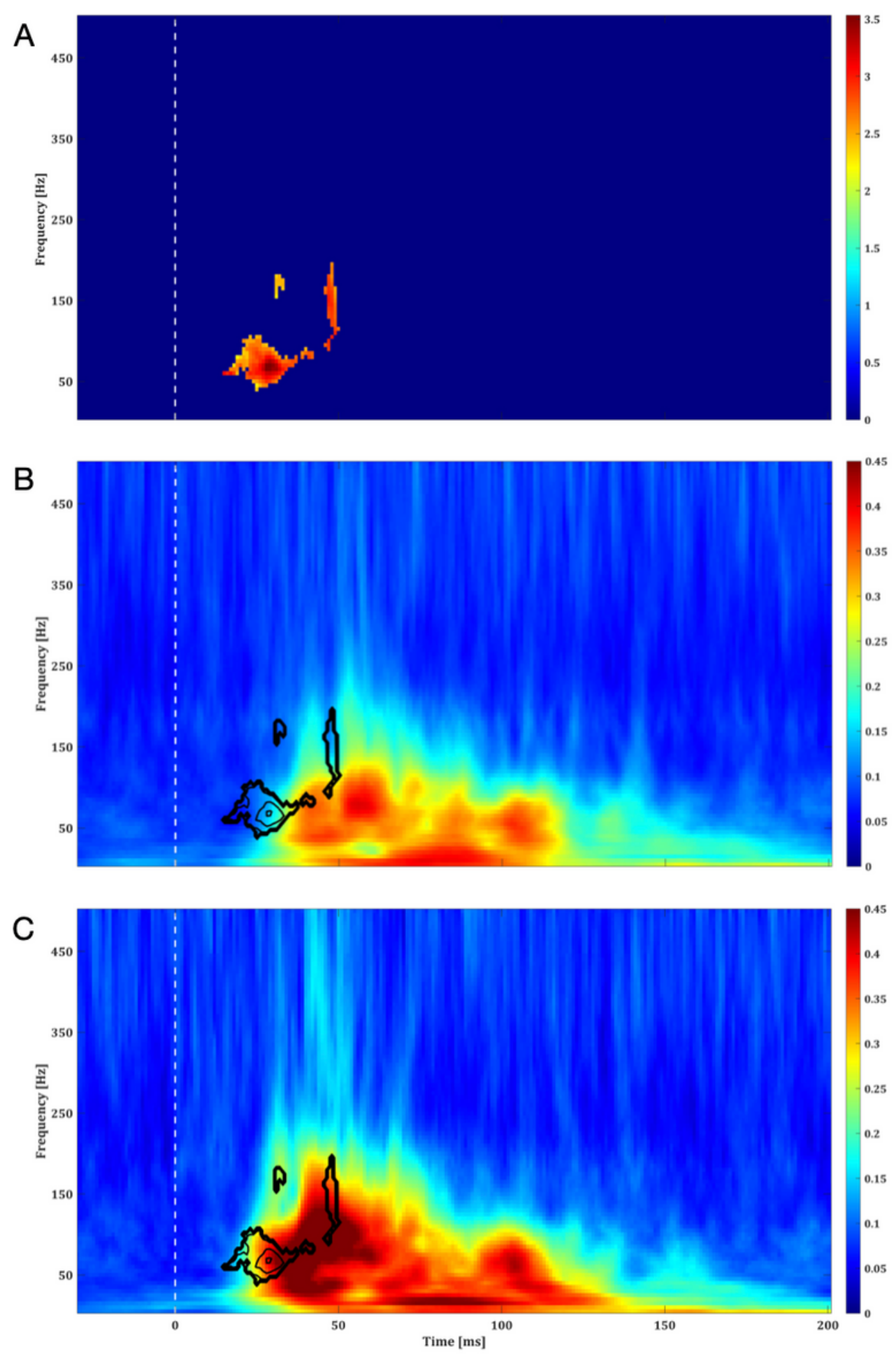

\section{Figure 5}

Inter-trial coherence of white matters contacts in the VOI. Panel A shows the results of the statistical comparison ( $p<0.01,1000$ permutations) between ITC panels of election contacts against couples of adjacent ones (see Methods). Statistical significance is limited in the interval 25-40 ms in the lower gammaband frequency (50-100 Hz). Panel B and C depict respectively the average of ITC panels for the election contacts (11 contacts) and for adjacent ones (19 contacts) as detailed in Table 2. Contours in black report regions of statistical significance as shown in Panel $A$. 

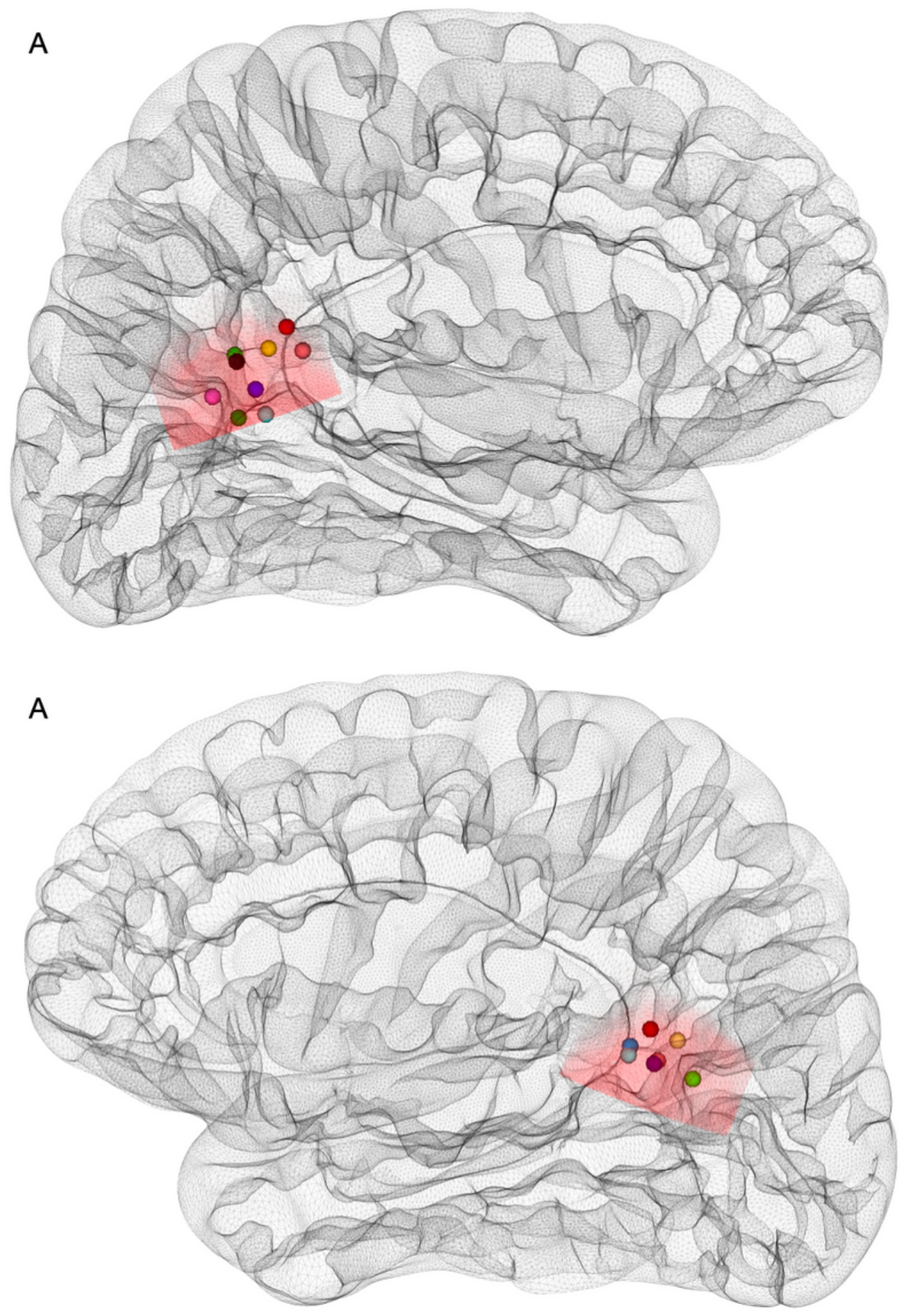

Figure 6

Relevant contact position. The position of each of the 16 "relevant contacts" identified by VEPs in relationship to the rendering of the $\mathrm{VOI}$ and related hemisphere (A: right hemisphere; $\mathrm{B}$ : left hemisphere) 


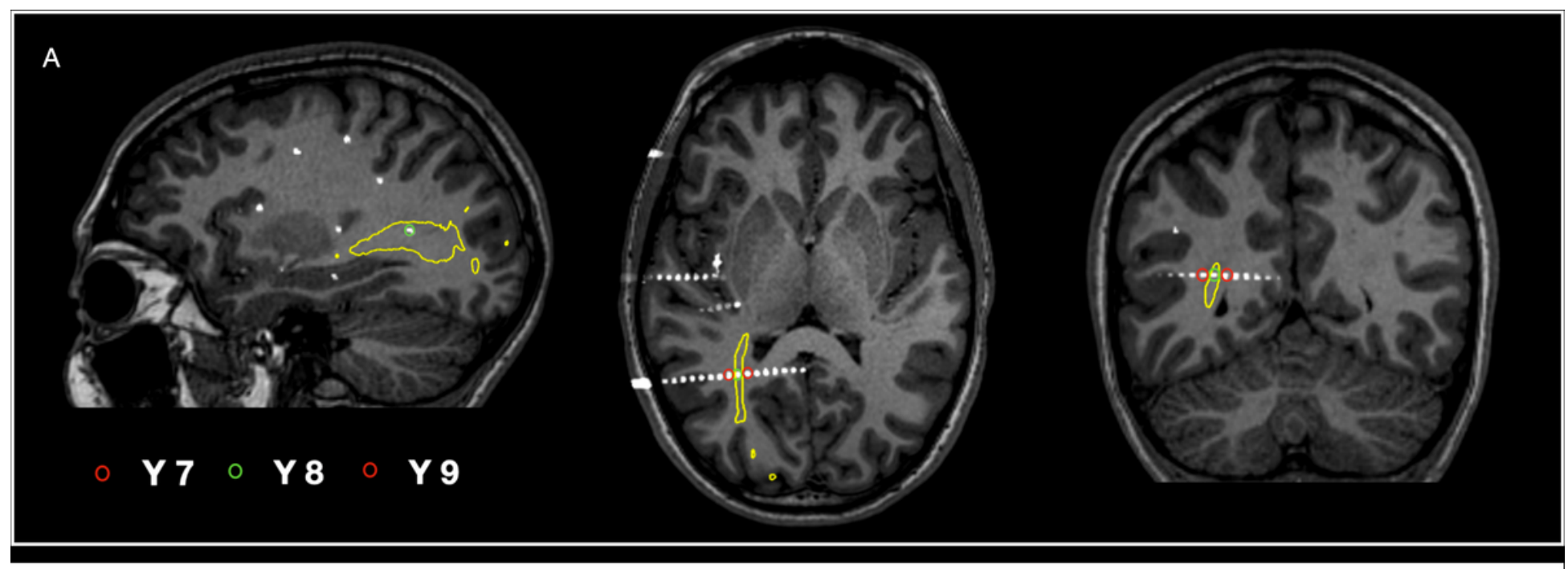

B
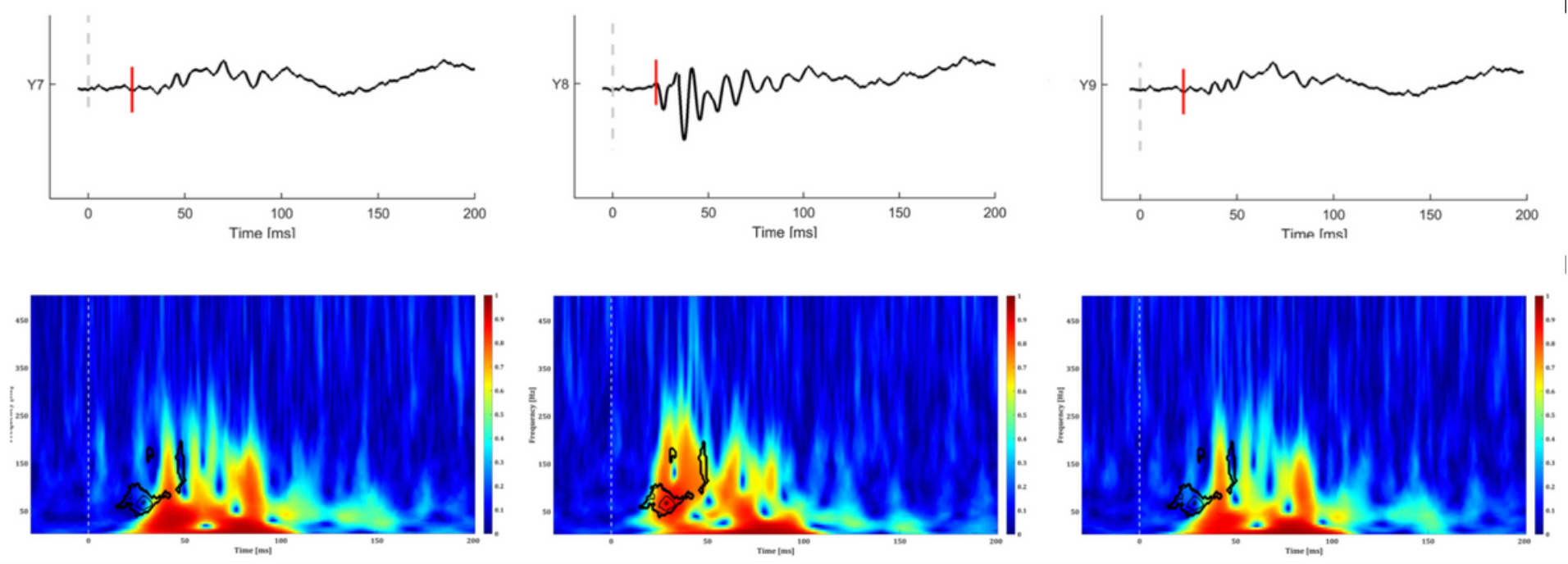

\section{Figure 7}

Single patient (patient 9) data representing the convergence between neurophysiological and tractographical data. Panel A shows the reciprocal position of the OR (in yellow) with the relevant (in green, Y8) and the adjacent (in red; $Y 7$ and $Y 9$ ) contacts. The upper portion of the panel B displays neurophysiological recordings at the level of the three contacts (only Y8 reports peculiar VEP features); the lower portion of the panel B represents the correspondent ITC results for each of the above contacts. Contours in black report regions of statistical significance as shown in Panel A of Figure 5.

\section{Supplementary Files}

This is a list of supplementary files associated with this preprint. Click to download.

- SupplVideo1.mov

- SupplVideo2.mov

- SupplementaryFile.docx 